\title{
NLRP3 Is Involved in the Maintenance of Cerebral Pericytes
}

\author{
Wenqiang Quan ${ }^{1,2}$, Qinghua Luo ${ }^{2}$, Qiqiang Tang ${ }^{3}$, Tomomi Furihata ${ }^{4}$, Dong $\mathrm{Li}^{1}$, \\ Klaus Fassbender ${ }^{2}$ and Yang Liu ${ }^{1,2 *}$
}

${ }^{1}$ Department of Clinical Laboratory, Tongji Hospital, Tongji University Medical School, Shanghai, China, ${ }^{2}$ Department of Neurology, Saarland University, Homburg, Germany, ${ }^{3}$ Department of Neurology, The First Affiliated Hospital of University of Science and Technology of China (Anhui Provincial Hospital), Hefei, China, ${ }^{4}$ Department of Clinical Pharmacy and

Experimental Therapeutics, School of Pharmacy, Tokyo University of Pharmacy and Life Sciences, Tokyo, Japan

\section{OPEN ACCESS}

Edited by:

Fabrice Dabertrand,

University of Colorado, United States

Reviewed by:

Kuniyuki Nakamura,

Kyushu University, Japan

Albert L. Gonzales,

University of Vermont, United States

*Correspondence:

Yang Liu

a.liu@mx.uni-saarland.de

Specialty section:

This article was submitted to

Non-Neuronal Cells,

a section of the journal

Frontiers in Cellular Neuroscience

Received: 17 May 2020 Accepted: 05 August 2020 Published: 21 August 2020

Citation: Quan W, Luo Q, Tang Q, Furihata T,

Li D, Fassbender K and Liu Y (2020) NLRP3 Is Involved in the Maintenance of Cerebral Pericytes.

Front. Cell. Neurosci. 14:276. doi: 10.3389/fncel.2020.00276
Pericytes play a central role in regulating the structure and function of capillaries in the brain. However, molecular mechanisms that drive pericyte proliferation and differentiation are unclear. In our study, we immunostained NACHT, LRR and PYD domainscontaining protein 3 (NLRP3)-deficient and wild-type littermate mice and observed that NLRP3 deficiency reduced platelet-derived growth factor receptor $\beta$ (PDGFR $\beta$ )-positive pericytes and collagen type IV immunoreactive vasculature in the brain. In Western blot analysis, PDGFR $\beta$ and CD13 proteins in isolated cerebral microvessels from the NLRP3-deficient mouse brain were decreased. We further treated cultured pericytes with NLRP3 inhibitor, MCC950, and demonstrated that NLRP3 inhibition attenuated cell proliferation but did not induce apoptosis. NLRP3 inhibition also decreased protein levels of PDGFR $\beta$ and CD13 in cultured pericytes. On the contrary, treatments with $I L-1 \beta$, the major product of NLRP3-contained inflammasome, increased protein levels of PDGFR $\beta$, and CD13 in cultured cells. The alteration of PDGFR $\beta$ and CD13 protein levels were correlated with the phosphorylation of AKT. Inhibition of AKT reduced both protein markers and abolished the effect of IL-1 $\beta$ activation in cultured pericytes. Thus, NLRP3 activation might be essential to maintain pericytes in the healthy brain through phosphorylating AKT. The potential adverse effects on the cerebral vascular pericytes should be considered in clinical therapies with NLRP3 inhibitors.

Keywords: Alzheimer's disease, neuroinflammation, NLRP3, pericyte, cerebral perfusion

\section{INTRODUCTION}

Brain pericytes wrapping around endothelial cells regulate various functions in the brain, which include blood-brain barrier (BBB) permeability, angiogenesis, and capillary hemodynamic responses (Sweeney et al., 2016). Pericytes express platelet-derived growth factor receptor $\beta$ (PDGFR $\beta$ ) and CD13. The binding of PDGFR $\beta$ with endothelial cells-released plateletderived growth factor (PDGF)-B is essential for pericyte proliferation and integration into the blood vessel (Lindahl et al., 1997). CD13 promotes angiogenesis in hypoxic tissues, and response to stimulation of angiogenic growth factors, such as vascular endothelial growth

Abbreviations: $A \beta$, amyloid $\beta$ peptide; $A D$, Alzheimer's disease; $A P P$, Alzheimer's precursor protein; $B B B$, blood-brain barrier; BDNF, brain-delivered neurotrophic factor; HBPC, human primary brain vascular pericytes; HBSS, Hanks' balanced salt solution; IL-1 $\beta$, interleukin-1 $\beta$; LPS, lipopolysaccharide; MyD88, myeloid differentiation primary response 88; NLRP, NACHT, LRR and PYD domains-containing protein; PCNA, proliferating cell nuclear antigen; PDGFR $\beta$, platelet-derived growth factor receptor $\beta$; TLR, Toll-like receptor; TNF- $\alpha$, tumor necrosis factor $\alpha$. 
factor, basic fibroblast growth factor, and transforming growth factor (Rangel et al., 2007). Deficiency of PDGFR $\beta$ decreases pericyte number, accumulates blood-derived fibrin/fibrinogen, reduces vasculature, and attenuates blood flow in the mouse brain, which finally leads to the white matter lesions characterized by loss of oligodendrocytes, demyelination, and axonal degeneration (Montagne et al., 2018). Growing evidence suggests that pericyte impairment mediates vascular dysfunction and contributes to the pathogenesis of Alzheimer's disease (AD; Love and Miners, 2016). In the AD human brain, pericytes are lost in association with increased BBB permeability at a very early disease stage (Sengillo et al., 2013; Nation et al., 2019). In AD mouse models that overexpress Alzheimer's precursor protein (APP) in neurons, the deletion of pericytes increases deposition of amyloid $\beta$ peptide $(A \beta)$ in both brain parenchyma and blood vessels, which potentially exaggerates cognitive deficits (Sagare et al., 2013). However, molecular mechanisms that regulate pericyte survival and activation in the brain are largely unknown.

Pericytes express pattern recognition receptors, such as Toll-like receptor 2 and 4 (TLR-2 and -4) and NACHT, LRR and PYD domains-containing protein 1 and 3 (NLRP-1 and -3; Guijarro-Muñoz et al., 2014; Leaf et al., 2017; Nyúl-Tóth et al., 2017). Cultured brain pericytes release cytokines and chemokines after being challenged with lipopolysaccharide (LPS), tumor necrosis factor (TNF)- $\alpha$ or E. coli infection (Kovac et al., 2011; Guijarro-Muñoz et al., 2014; Nyúl-Tóth et al., 2017). Cultured pericytes secret active interleukin (IL)-1 $\beta$ when they are intracellularly stimulated with LPS, although how NLRP3contained inflammasome is activated remains unclear (NyúlTóth et al., 2017). It is interesting to ask whether innate immune signaling regulates cell fate and functions of pericytes in the brain.

In $\mathrm{AD}$ research, NLRP3-contained inflammasome attracted great attention, as it is activated in $\mathrm{AD}$ brain and potentially mediates microglial inflammatory responses, exaggerates $A \beta$ and Tau protein aggregation in APP or Tau-transgenic mice (Heneka et al., 2013; Venegas et al., 2017; Ising et al., 2019; Stancu et al., 2019). NLRP3 is considered as a promising therapeutic target for AD patients (Dempsey et al., 2017). However, the effects of NLRP3 activation on pericytes and vascular dysfunction were not addressed. The animal models used in published studies have also limited $\mathrm{AD}$-associated vascular pathology. Thus, whether NLRP3 inhibition protects or damages microvascular circulation in the $\mathrm{AD}$ brain remains unclear. Moreover, $\mathrm{AD}$ pathology is mainly localized in temporal and parietal lobes, instead of covering the whole brain. Between AD lesion sites as shown with $A \beta$ deposits, neurofibrillary tangles, and gliosis, the brain tissues are relatively or absolutely healthy (Deture and Dickson, 2019). It is, therefore, necessary to understand the physiological function of NLRP3 in brain pericytes, which is helpful to predict potential off-target effects of NLRP3 inhibitors in the future anti-AD therapies.

In this study, we used NLRP3-knockout mice and treated cultured pericytes with NLRP3 inhibitor, MCC950, or IL$1 \beta$, a major product of NLRP3-contained inflammasome. We observed that NLRP3 might be essential for the maintenance of healthy pericytes in the brain. We further observed that AKT (also known as protein kinase B) might mediate the physiological function of NLRP3 in pericytes.

\section{MATERIALS AND METHODS}

\section{Mice}

NLRP3-encoding gene knockout (NLRP3-/-) mice were kindly provided by N. Fasel (University of Lausanne, Lausanne, Switzerland; Martinon et al., 2006). Mice with the knockout of gene encoding myeloid differentiation primary response 88 $\left(\mathrm{MyD}^{-/-} 8^{-}\right.$) were originally provided by S. Akira and K. Takeda (Osaka University, Osaka, Japan; Adachi et al., 1998). Breeding between heterozygous mutants $(+/-)$ on a C57BL/6 background was used to maintain mouse colonies. Mice were compared only between littermates. Animal experiments were performed following all relevant national rules and were authorized by the local research ethics committee.

\section{Tissue Collection and Isolation of Blood Vessels}

Animals were euthanized by inhalation of isoflurane and perfused with ice-cold phosphate-buffered saline. The brain was removed and divided. The left hemisphere was immediately fixed in $4 \%$ paraformaldehyde (Sigma-Aldrich Chemie $\mathrm{GmbH}$, Taufkirchen, Germany) for immunohistochemistry. The cortex and hippocampus from the right hemisphere were carefully dissected and brain vessel fragments were isolated according to the published protocol (Boulay et al., 2015). Briefly, brain tissues were homogenized in HEPES-contained Hanks' balanced salt solution (HBSS) and centrifuged at 4,400 $g$ in HEPES-HBSS buffer supplemented with dextran from Leuconostoc spp. (molecular weight $\sim 70,000$; Sigma-Aldrich) to delete myelin. The vessel pellet was re-suspended in HEPES-HBSS buffer supplemented with $1 \%$ bovine serum albumin (Sigma-Aldrich) and filtered with $20 \mu \mathrm{m}$-mesh. The blood vessel fragments were collected on the top of the filter for biochemical analysis and stored at $-80^{\circ} \mathrm{C}$ for biochemical analysis.

\section{Histological Analysis}

To analyze pericytes in capillaries, serial $30-\mu \mathrm{m}$-thick sagittal sections were cut from the dehydrated and cryoembedded left brain hemisphere with a Leica cryostat (Leica Mikrosysteme Vertrieb, Wetzlar, Germany). Three sections per mouse with $300 \mu \mathrm{m}$ of an interval between neighboring layers were used. Antigen retrieval was performed by heating sections in $10 \mu \mathrm{M}$ citrate buffer $(\mathrm{pH}=6)$. After blocking with $5 \%$ goat serum in $\mathrm{PBS} / 0.3 \%$ Triton $\mathrm{X}-100$, brain sections were incubated with rabbit anti-PDGFR $\beta$ monoclonal antibody (clone: 28E1; Cell Signaling Technology Europe, Frankfurt am Main, Germany) at $4^{\circ} \mathrm{C}$ overnight and then Alexa488-conjugated goat anti-rabbit IgG (Thermo Fisher Scientific, Darmstadt, Germany) at room temperature for $1 \mathrm{~h}$. Thereafter, brain sections were further stained with biotin-labeled Griffonia simplicifolia Lectin I isolectin B4 (Catalog: B-1205; Vector Laboratories, Burlingame, CA, USA) and Cy3-conjugated streptavidin (Roche Applied Science, Mannheim, Germany). The whole cortex was imaged under a Zeiss AxioImager.Z2 microscope (Carl 
Zeiss Microscopy GmbH, Göttingen, Germany) equipped with a Stereo Investigator system (MBF Bioscience, Williston, VT, USA). Ten regions per section were randomly chosen under a $40 \times$ objective. Blood vessels with $<6 \mu \mathrm{m}$ of diameter were examined. Fluorescence-labeled areas were measured with ImageJ software ${ }^{1}$. The coverage of pericytes was calculated as a ratio of PDGFR $\beta /$ isolectin B4-positive staining area.

To detect the expression of NLRP3 in pericytes, brain sections were incubated at $4^{\circ} \mathrm{C}$ overnight with mouse anti-NLRP3 monoclonal antibody (clone: Cryo-2; AdipoGen Life Sciences, San Diego, CA, USA), which was followed by incubation with Cy3-conjugated goat anti-mouse IgG (Jackson ImmunoResearch Europe Ltd., Cambridgeshire, UK) at room temperature for $1 \mathrm{~h}$. Thereafter, brain sections were further stained with rabbit anti-PDGFR $\beta$ monoclonal antibody and Alexa488-conjugated goat anti-rabbit IgG as described above. Stack images were acquired with a Zeiss AxioImager.Z2 microscope under a $63 \times$ oil objective with an interval of $0.2 \mu \mathrm{m}$ between neighboring layers, processed with deconvolution and finally $\mathrm{Z}$-projected with maximum intensity.

For analysis of the impairment of BBB in NLRP3-deficient mice, brain sections from NLRP3 - knockout and wild-type mice were stained with Alexa488-conjugated goat anti-mouse IgG (Thermo Fisher Scientific) after blocking with goat serum as we did in a previous study (Hao et al., 2011), and co-stained with biotinylated isolectin B4 and Cy3-conjugated streptavidin.

To quantify vasculature in the brain, our established protocol was used (Decker et al., 2018). The left hemisphere was embedded in paraffin and $40-\mu \mathrm{m}$-thick sagittal sections were serially cut. Four serial sections per mouse with $400 \mu \mathrm{m}$ of distance in between were deparaffinized, heated at $80^{\circ} \mathrm{C}$ in citrate buffer $(10 \mathrm{mM}, \mathrm{pH}=6)$ for $1 \mathrm{~h}$, and digested with Digest-All 3 (Pepsin; Thermo Fisher Scientific) for $20 \mathrm{~min}$. Thereafter, brain sections were stained with rabbit anti-collagen IV polyclonal antibody (Catalog: \#ab6586; Abcam, Cambridge, UK) and Alexa488-conjugated goat anti-rabbit IgG (Thermo Fisher Scientific). After being mounted, the whole brain including the hippocampus and cortex was imaged with Microlucida (MBF Bioscience). The length and branching points of collagen type IV staining-positive blood vessels were analyzed with free software, AngioTool ${ }^{2}$ (Zudaire et al., 2011). The parameters of analysis for all compared samples were kept constant. The length and branching points were adjusted with an area of interest.

\section{Western Blot Analysis}

Isolated blood vessels were lysed in RIPA buffer [50 mM Tris ( $\mathrm{pH}$ 8.0), $150 \mathrm{mM} \mathrm{NaCl}, 0.1 \%$ SDS, $0.5 \%$ sodium deoxycholate, $1 \%$ NP-40, and $5 \mathrm{mM}$ EDTA] supplemented with protease inhibitor cocktail (Roche Applied Science) on ice. The tissue lysate was sonicated before being loaded onto 10\% SDS-PAGE. For Western blot detection, rabbit monoclonal antibodies against PDGFR $\beta$ and CD13/APN (clone: 28E1 and D6V1W, respectively; Cell

\footnotetext{
${ }^{1}$ https://imagej.nih.gov/ij/

${ }^{2}$ https://ccrod.cancer.gov/confluence/display/ROB2/
}

Signaling Technology Europe) were used. In the same sample, $\beta$-actin was detected as a loading control using a rabbit monoclonal antibody (clone: 13E5; Cell Signaling Technology Europe). Western blots were visualized via the ECL method (PerkinElmer LAS GmbH, Rodgau, Germany). Densitometric analysis of band densities was performed with ImageJ software. For each sample, the protein level was calculated as a ratio of target protein $/ \beta$-actin.

\section{Culture of Pericytes}

Human primary brain vascular pericytes (HBPC) were immortalized by infecting cells with tsSV40T lentiviral particles (Umehara et al., 2018). The selected immortalized HBPC clone 37 (hereafter referred to as $\mathrm{HBPC} / \mathrm{ci} 37$ ) was used for our study. $\mathrm{HBPC} / \mathrm{ci} 37$ cells were cultured at $33^{\circ} \mathrm{C}$ with $5 \% \mathrm{CO}_{2} / 95 \%$ air in pericyte medium (Catalog: \#1201; Sciencell Research Laboratories, Carlsbad, CA, USA) containing 2\% (v/v) fetal bovine serum, $1 \%(\mathrm{w} / \mathrm{v})$ pericyte growth factors, and penicillinstreptomycin. Culture flasks and plates were treated with Collagen Coating Solution (Catalog: \#125-50; Sigma-Aldrich). $\mathrm{HBPC} / \mathrm{ci} 37$ cells were used at 40-60 passages in this study.

\section{Analysis of Pericyte Proliferation and Apoptosis}

Pericytes were seeded at $1.0 \times 10^{4}$ cells on 96 -well plate/100 $\mu \mathrm{l}$ (day 0), and cultured in pericyte medium containing NLRP3 inhibitor, MCC950 (Catalog: \#PZ0280; Sigma-Aldrich), at $0,25,50$ and $100 \mathrm{nM}$, or containing recombinant human IL-1 $\beta$ (Catalog: \#201-LB; R\&D Systems, Wiesbaden, Germany) at $0,5,10$ and $50 \mathrm{ng} / \mathrm{ml}$. The cell survival was detected with MTT-based Cell Proliferation Kit I (Catalog: \#11465007001; Sigma-Aldrich) on days 1, 2, 3, 4, 5, 6 and 7. In MTT assay, yellow and water-soluble 3-(4,5-dimethylthiazol-2-yl)-2,5diphenyl tetrazolium bromide (MTT) enters viable cells and passes into the mitochondria where it is reduced by succinate dehydrogenase to an insoluble, dark purple formazan product. The measured absorbance as shown with optical density (OD) at $590 \mathrm{~nm}$ is proportional to the number of viable cells.

To further detect cell death and proliferation of pericytes, cells were cultured in 12 -well plate at $5.0 \times 10^{5}$ cells/well, and treated with MCC950 as described in MTT assay. After $24 \mathrm{~h}$, pericytes were collected and lysed in RIPA buffer. Quantitative Western blot was used with rabbit monoclonal antibody against cleaved caspase-3 (clone: 5A1E; Cell Signaling Technology Europe), mouse monoclonal antibody against proliferating cell nuclear antigen (PCNA; clone: PC10; Cell Signaling Technology Europe) and rabbit monoclonal antibody against Ki-67 (clone: SP6; Abcam). $\alpha$-tubulin and $\beta$-actin were detected as internal control with mouse monoclonal antibody (clone: DM1A; Abcam) and rabbit monoclonal antibody (clone: 13E5; Cell Signaling Technology Europe), respectively.

In this experiment, we also detected NLRP3 and cleaved caspase- 1 in the cell lysate from pericytes with and without treatment of MCC950, with rabbit monoclonal antibodies against NLRP3 and cleaved caspase-1 (Asp297; clone D4D8T and D57A2; Cell Signaling Technology Europe), respectively. 


\section{Treatments of Pericytes for Detection of PDGFR $\beta$ and CD13 and Phosphorylated \\ Kinases}

Pericytes were cultured in a 12 -well plate at $5.0 \times 10^{5}$ cells/well. Before experiments, we replaced the culture medium with serum-free pericyte medium and cultured cells at $37^{\circ} \mathrm{C}$ for 3 days to facilitate cell differentiation (Umehara et al., 2018). Thereafter, pericytes were treated for $24 \mathrm{~h}$ with MCC950, at $0,25,50$ and $100 \mathrm{nM}$, recombinant human IL-1 $\beta$ (Catalog: \#201-LB; R\&D Systems) at 0, 5, 10 and $50 \mathrm{ng} / \mathrm{ml}$, or AKT Inhibitor VIII (Catalog: \#124018; Sigma-Aldrich) at 0, 0.5, 1 and $5 \mu \mathrm{M}$. To investigate whether AKT mediates the effect of IL-1 $\beta$, pericytes were pre-treated with $1 \mu \mathrm{M}$ AKT inhibitor VIII for $1 \mathrm{~h}$ and then incubated with IL- $1 \beta$ at various concentrations in the presence of AKT inhibitor for $24 \mathrm{~h}$. The cell lysate was prepared in RIPA buffer supplemented with protease inhibitor cocktail (Roche Applied Science) and phosphatase inhibitors (50 nM okadaic acid, $5 \mathrm{mM}$ sodium pyrophosphate, and $50 \mathrm{mM} \mathrm{NaF}$; Sigma-Aldrich). For quantitative Western blot, the following antibodies were used: rabbit monoclonal antibodies against PDGFR $\beta$, CD13/APN, phosphorylated AKT (Ser473), phosphorylated ERK1/2 (Thr202/Tyr204),

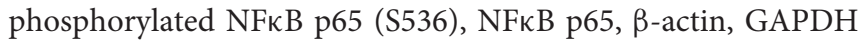
(clone: 28E1, D6V1W, D9E, D13.14.4E, 93H1, D14E12, 13E5, and 14C10, respectively; Cell Signaling Technology Europe), rabbit polyclonal antibodies against AKT and phosphorylated GSK-3 $\beta$ (Ser9; Catalog: \#9272 and Catalog: \#9336, respectively; Cell Signaling Technology Europe) and mouse monoclonal antibodies against ERK1/2 and GSK-3 $\beta$ (clone: L34F12 and 3D10, respectively; Cell Signaling Technology Europe) and $\alpha$-tubulin (clone: DM1A; Abcam).

\section{Statistics}

Data were presented as mean \pm SEM for mice and mean \pm SD for cells. For multiple comparisons, one-way or two-way ANOVA followed by Bonferroni or Tukey post hoc test. Two independentsamples Students $t$-test was used to compare means for two groups of cases. All statistical analyses were performed with GraphPad Prism 5 version 5.01 for Windows (GraphPad Software, San Diego, CA, USA). Statistical significance was set at $p<0.05$.

\section{RESULTS}

\section{NLRP3 Deficiency Reduces Pericyte Cell Coverage and Decreases Protein Levels of PDGFR $\beta$ and CD13 in the Brain}

To explore the effects of NLRP3 on the maintenance of pericytes in the brain, we first detected the expression of NLRP3 in pericytes. In brain sections, we observed widely distributed NLRP3-immune reactive cell bodies and processes, part of which were co-stained by PDGFR $\beta$-specific antibodies (Figure 1A), which suggests that pericytes express NLRP3. Then, we estimated the coverage of PDGFR $\beta$-positive cells in brains from 9-month-old NLRP3-knockout (NLRP3-/- and $\mathrm{NLRP}^{+/-}$) and wild-type (NLRP3 ${ }^{+/+}$) littermate mice. As shown in Figures 1B,C, deficiency of NLRP3 significantly decreased the coverage of PDGFR $\beta$-immune reactive cells in microvessels with $<6 \mu \mathrm{m}$ of diameter in a gene dose-dependent manner as compared with that in NLRP3-wildtype mice (one-way ANOVA, $p<0.05 ; n=4$ per group). We continued to isolate blood vessels from brains of 9-month-old NLRP3 ${ }^{-/-}$, $\mathrm{NLRP}^{+/-}$and $\mathrm{NLRP}^{+/+}$littermate mice for the detection of pericyte protein markers, PDGFR $\beta$, and CD13. We observed that the deletion of NLRP3 significantly reduced PDGFR $\beta$ and $\mathrm{CD} 13$ proteins in the cerebral blood vessels also in a gene dose-dependent manner (Figures 1D,E; one-way ANOVA, $p<0.05 ; n \geq 7$ per group). Unfortunately, we failed to detect cleaved caspase- 3 and PCNA in the tissue lysate of blood vessels (data not shown), which are markers for cell apoptosis and cell proliferation, respectively.

In further experiments, we asked whether innate immune signaling serves a common effect on pericyte survival in the brain. We detected PDGFR $\beta$ and $\mathrm{CD} 13$ proteins in cerebral blood vessels isolated from 6-month-old MyD88 ${ }^{-/-}$, ${\mathrm{MyD} 88^{+/-}}$and ${\mathrm{MyD} 88^{+/+}}^{+1}$ littermate mice. MyD88 is a common adaptor down-stream to most TLRs and mediates the inflammatory activation of IL-1 $\beta$ (O'Neill and Bowie, 2007). We observed that protein levels of CD13 and PDGFR $\beta$ were significantly lower in MyD88-deficient mice than in MyD88wildtype controls (Figures 1F,G; one-way ANOVA, $p<0.05$; $n \geq 6$ per group).

\section{NLRP3 Deficiency Reduces Vasculature in the Brain}

Pericytes are essential for the development of cerebral circulation. Dysfunction of pericytes reduces vasculature and increases the permeability of BBB (Sweeney et al., 2016; Montagne et al., 2018). We asked whether NLRP3 deficiency affects the structure of cerebral blood vessels. We observed that, in 9-month-old mouse brains, deficiency of NLRP3 significantly reduced the total length and branching points of collagen type IV-positive blood vessels (Figures 2A-C; one-way ANOVA, $p<0.05 ; n \geq 6$ per group). The reduction of brain vasculature was dependent on the copies of the NLRP3encoding gene. However, we did not detect IgG leakage into the brain parenchyma, which suggested that the intactness of BBB in NLRP3-deficient mice was not severely damaged (see Figure 2D).

\section{NLRP3 Inhibition Attenuates Cell Proliferation in Cultured Pericytes}

After we observed that NLRP3 deficiency decreased the number of pericytes in the brain, we continued to investigate whether NLRP3 directly regulates the proliferation and death of pericytes. We detected NLRP3 proteins in our cultured pericytes with different passaging numbers (Figure 3A). We also detected cleaved caspase-1 in pericytes, with the remarked reduction of proteins after cells were treated with NLRP3 inhibitor, MCC950 (Figure 3B). Thus, the NLRP3-caspase-1 signaling pathway is active in pericytes and potentially regulates the cellular function. Activated caspase- 1 cleaves pro-IL-1 $\beta$ into active IL-1 $\beta$ 
A
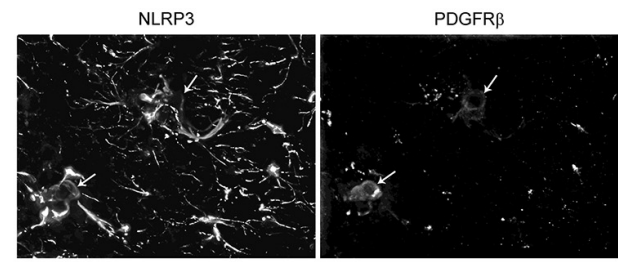

PDGFR $\beta$

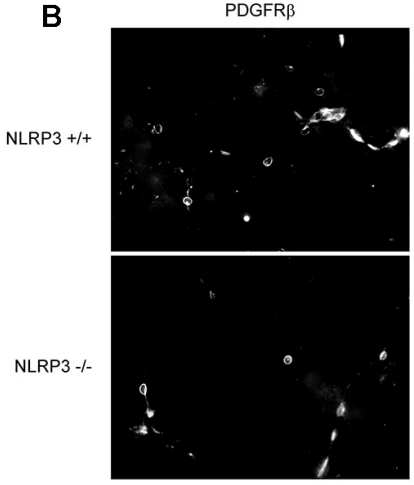

Isolectin

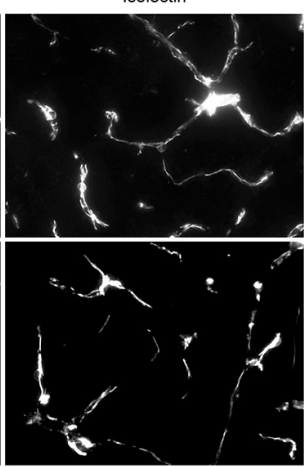

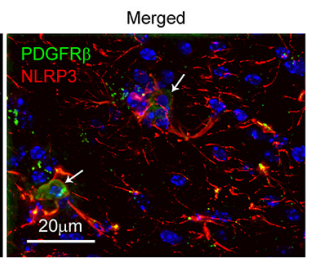

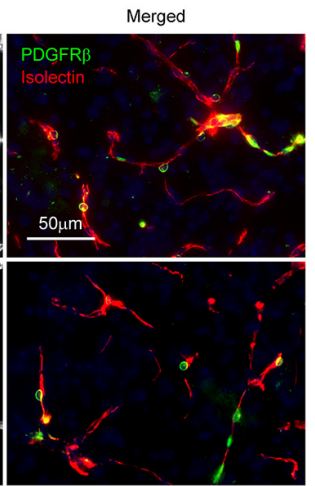

C

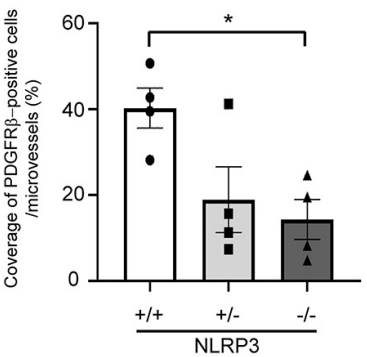

D
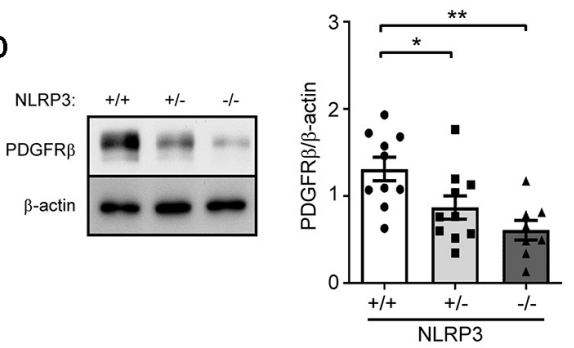

E
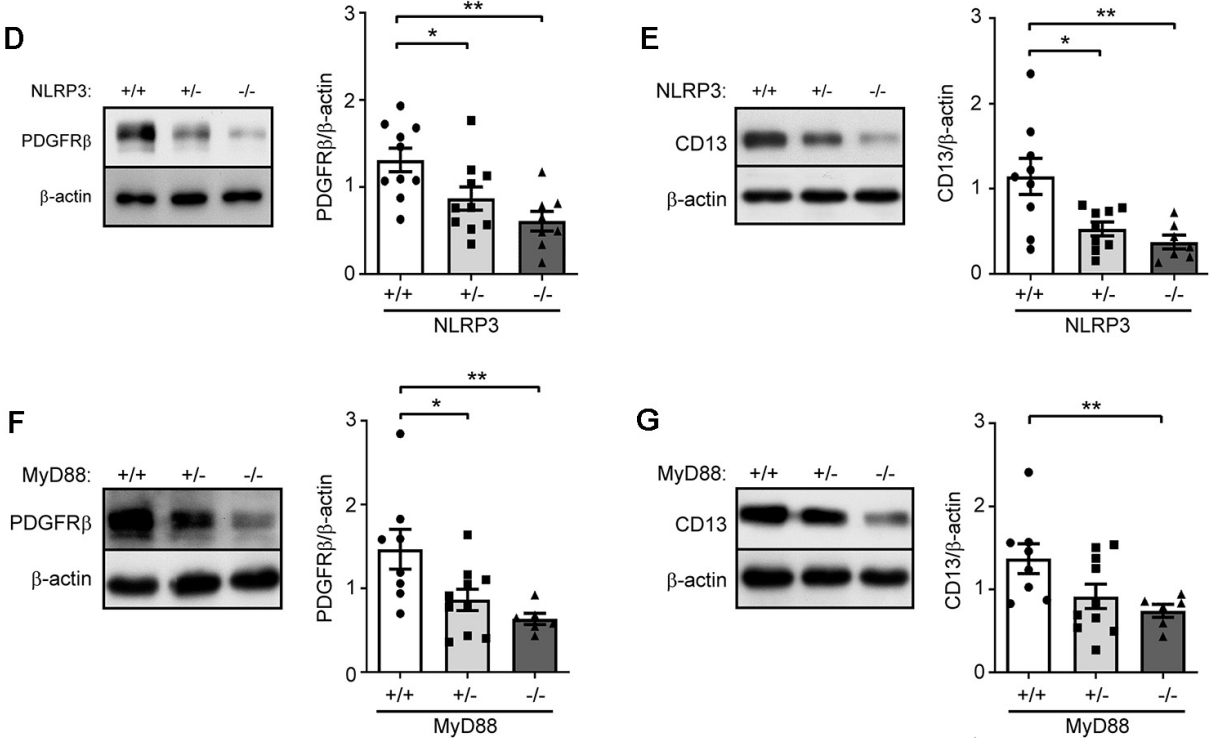

FIGURE 1 | NLRP3 deficiency reduces pericyte cell coverage and decreases protein levels of PDGFR $\beta$ and CD13 in the brain. (A) Nine-month-old mouse brains were co-stained for NLRP3 and PDGFR $\beta$. PDGFRß-immune reactive cell bodies (in green; marked with arrows) were stained by NLRP3-specific antibodies (in red). (B) Brain tissues from 9-month-old NLRP3-knockout (-/- and +/-) and wild-type (+/+) littermate mice were then co-stained for PDGFR (with anti-PDGFR $\beta$ antibodies, in green) and endothelial cells (with isolectin B4, in red). (C) The coverage of PDGFR $\beta$-positive pericytes was calculated as a ratio of PDGFR $\beta$ /isolectin B4-positive area. One-way ANOVA followed by Tukey post hoc test, $n=4$ per group. (D-G) Nine-month-old NLRP3, and 6-month-old MyD88 littermate mice with homozygous (-/-) and heterozygous (+/-) knockout, and wild-type (+/+) of nlrp3 and myd88 genes, respectively, were analyzed for protein levels of PDGFR $\beta$ and CD13 in isolated cerebral blood vessels. One-way ANOVA followed by Bonferroni post hoc test, $n=10,10$ and 8 for NLRP3 (+/+, $+/-$ and $-/-)$ mice in PDGFR $\beta$ detection and $n=9,9$ and 7 for NLRP3 (+/+, +/- and -/-) mice in CD13 detection; $n=8,10$ and 6 for MyD88 (+/+, $+/-$ and -//) mice in the detection of both PDGFR $\beta$ and CD13. ${ }^{*} p<0.05$ and ${ }^{* *} p<0.01$.

(Gross et al., 2011). However, we were not able to show that NLRP3 inhibition reduced IL-1 $\beta$ secretion as the IL-1 $\beta$ release from non-activated pericytes was undetectable (data are not shown).
Then, we investigated whether NLRP3 regulates pericyte proliferation. After treating cultured pericytes with MCC950 at different concentrations, we observed that NLRP3 inhibition significantly reduced the conversion of MTT into its colorful 

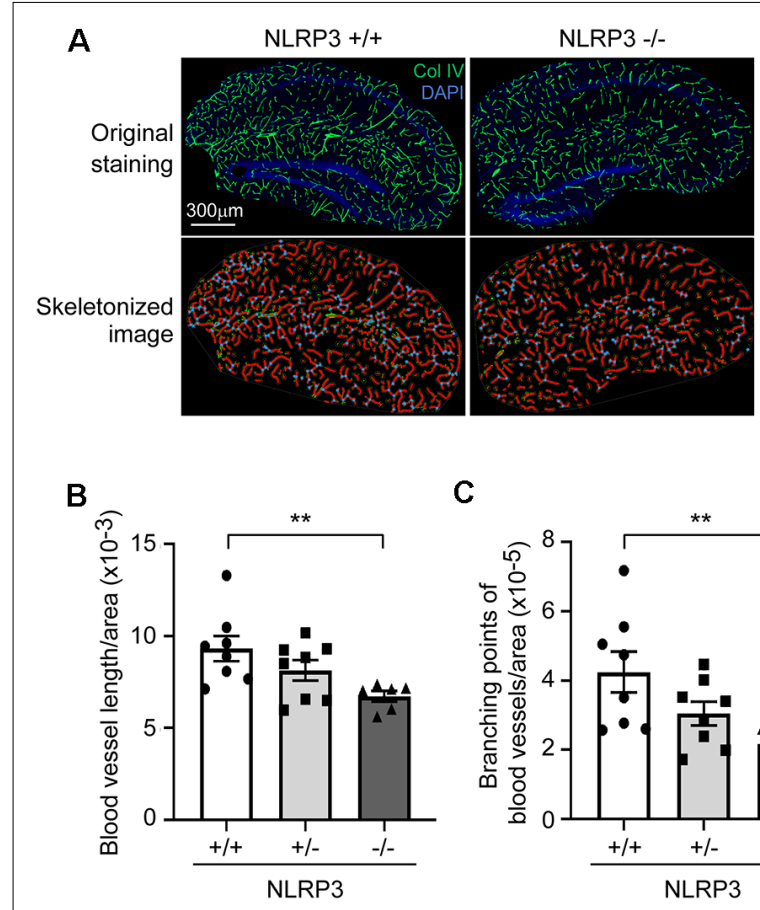

C
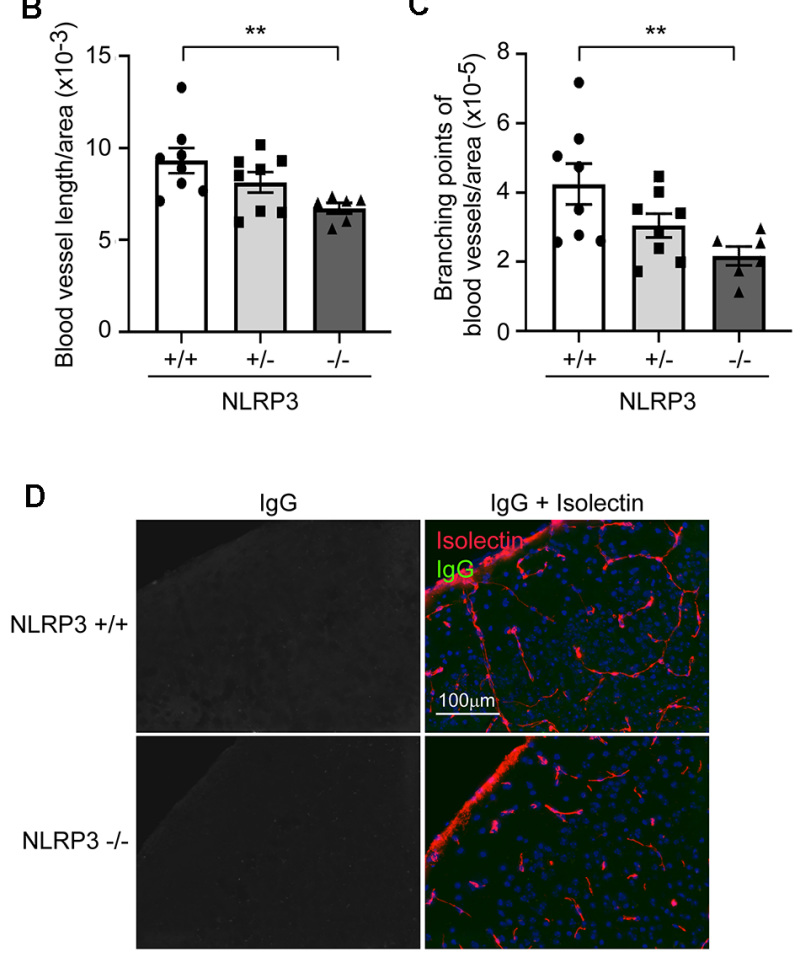

FIGURE 2 | NLRP3 deficiency reduces vasculature in the brain. (A) The brains of 9 -month-old littermate mice with homozygous $(-/-)$, heterozygous $(+/-)$, and wild-type (+/+) of nlrp3 gene were stained for collagen type IV (Col IV). The blood vessels in the hippocampus were thresholded and skeletonized. The skeleton representation of vasculature is shown in red and branching points of blood vessels are in blue. $(\mathbf{B}, \mathbf{C})$ The total length and branching points of blood vessels were calculated and adjusted by area of analysis. One-way ANOVA followed by Bonferroni post hoc test, $n=8$, 8, and 6 for NLRP3 (+/+, +/- and -/-) mice, respectively. ${ }^{\star *} p<0.01$.

(D) Nine-month-old NLRP3-deficient and wild-type mouse brains were further stained for mouse lgG and isolectin B4. We could not detect mouse lgG in the brain parenchyma.

product, formazan, in a dose-dependent manner (Figure 3C; two-way ANOVA, $p<0.05 ; n=4$ per group). The amount of formazan as shown with $\mathrm{OD}$ values is proportional to the number of viable cells. In further experiments, we detected no cleavage of caspase-3 in MCC950-treated cells (Figure 3D), while MCC950 treatments significantly decreased protein levels of both PCNA (Figures 3E,F; one-way ANOVA, $p<0.05 ; n=3$ per group) and Ki-67

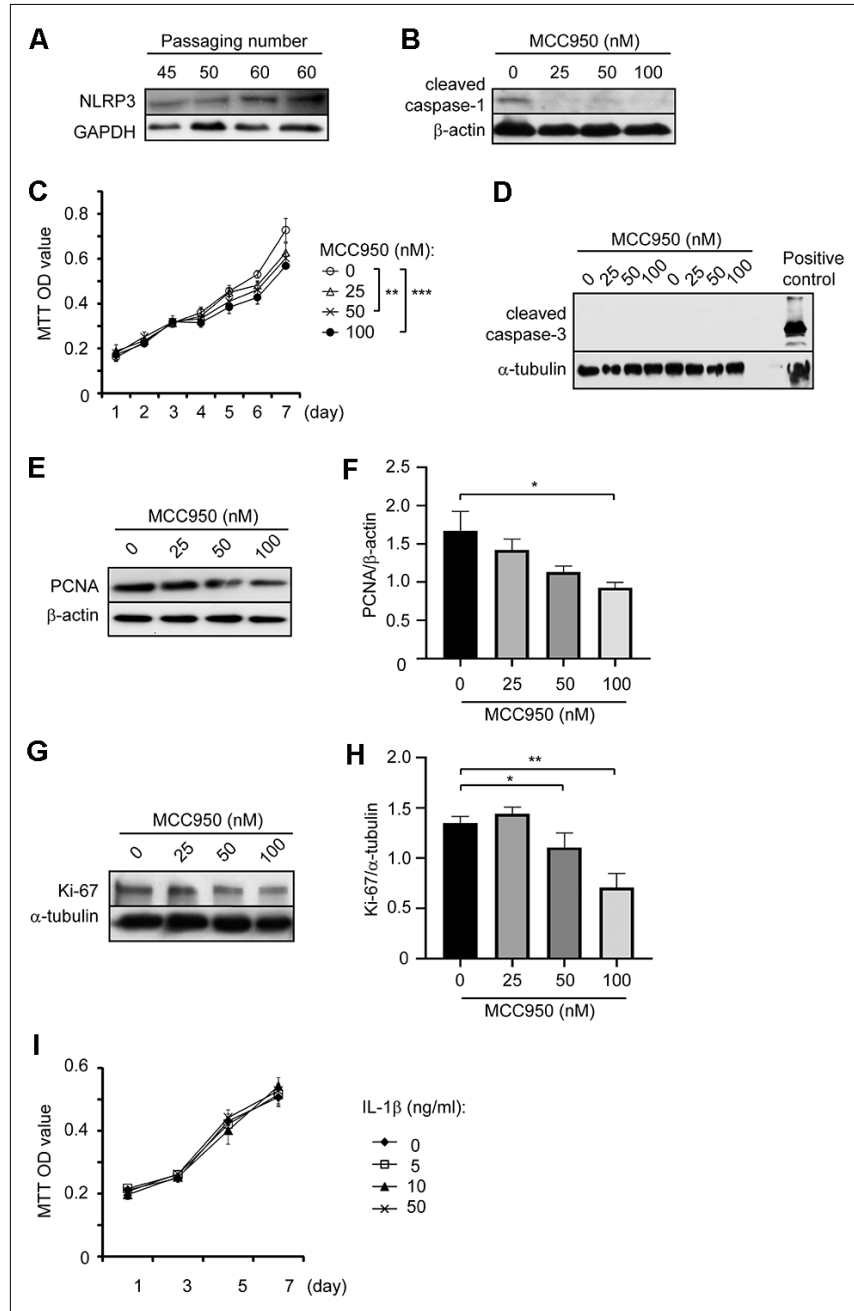

FIGURE 3 | NLRP3 inhibition attenuates cell proliferation in cultured pericytes. (A) The cell lysates collected from cultured pericytes with different passaging numbers were detected for NLRP3 with Western blot. (B) Pericytes were treated with NLRP3 inhibitor, MCC950, at 0, 25, 50, and $100 \mathrm{nM}$ for $24 \mathrm{~h}$ and then detected for cleaved caspase-1. After inhibition of NLRP3, cleaved caspase-1 was nearly undetectable. (C) Cultured pericytes were treated with MCC950 with various doses and analyzed for proliferation with MTT assay every day for 7 days. Two-way ANOVA followed by Tukey post hoc test, $n=4$ per group. ${ }^{\star *} p<0.01$ and ${ }^{* * *} p<0.001$. (D-H) Pericytes were cultured and treated with MCC950 at indicated concentrations for $24 \mathrm{~h}$. Cell lysates were detected for cleaved caspase-3, PCNA, and Ki-67 with a quantitative Western blot. As a positive control for cleavage of caspase-3, the brain lysate from neuronal ATG5-deficient mice was used. The result in (D) shows one experiment representative of four independent experiments. The inhibition of NLRP3 reduces protein levels of PCNA and Ki-67 in a dose-dependent manner. One-way ANOVA followed by Tukey post hoc test, $n=3$ per group for PCNA, and $n=4$ per group for Ki-67. ${ }^{*} p<0.05$ and ${ }^{* *} p<0.01$. (I) cultured pericytes were further treated with recombinant IL-1 $\beta$ at $0,5,10$, and $50 \mathrm{ng} / \mathrm{ml}$ and analyzed with MTT assay every 2 days for 7 days. Two-way ANOVA analysis did not show the effects of IL-1 $\beta$ on cell proliferation, $n=3$ per group.

(Figures 3G,H; one-way ANOVA, $p<0.05 ; n=4$ per group), which are two typical protein markers for cell proliferation. Thus, inhibition of NLRP3 suppresses the proliferation of pericytes. 

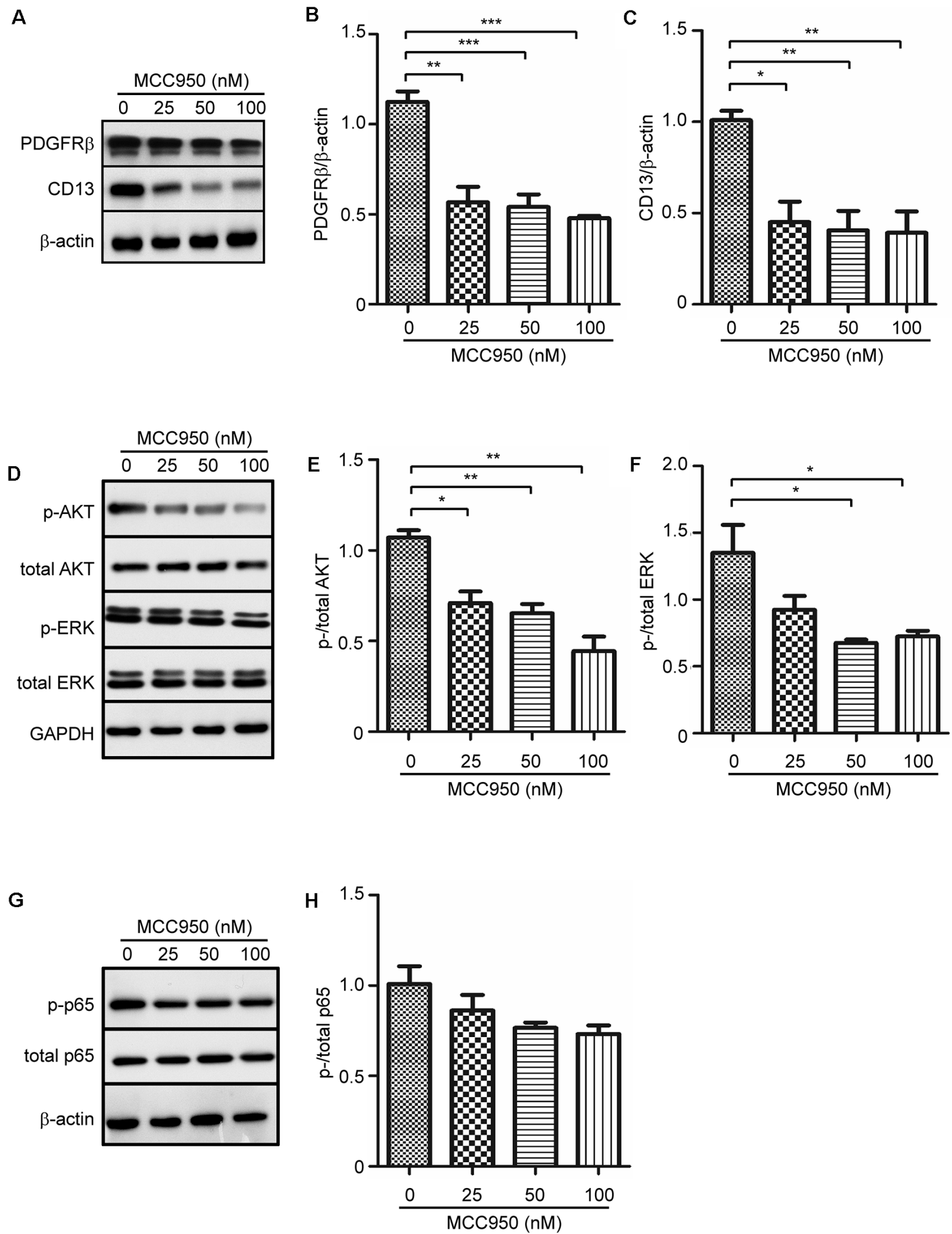

FIGURE 4 | NLRP3 inhibition attenuates protein expression of PDGFR $\beta$ and CD13 and inhibits phosphorylation of AKT and ERK in cultured pericytes. Pericytes were cultured and treated with MCC950 at 0, 25, 50, and $100 \mathrm{nM}$ for 24 h. (A,D,G) Western blot was used to detect PDGFR 3 and CD13, as well as phosphorylated and total protein levels of AKT, ERK, and NFKB p65. (B,C,E,F) Inhibition of NLRP3 reduces protein levels of PDGFR $\beta$ and CD13 and inhibits phosphorylation of AKT and ERK with a dose-dependent pattern. one-way ANOVA followed by Tukey post hoc test, $n=4$ per group. ${ }^{*} p<0.05,{ }^{* *} p<0.01$ and ${ }^{* \star *} p<0.001$. (H) Phosphorylation of NFKB p65 is not significantly changed by inhibition of NLRP3. One-way ANOVA, $n=3$ per group. 

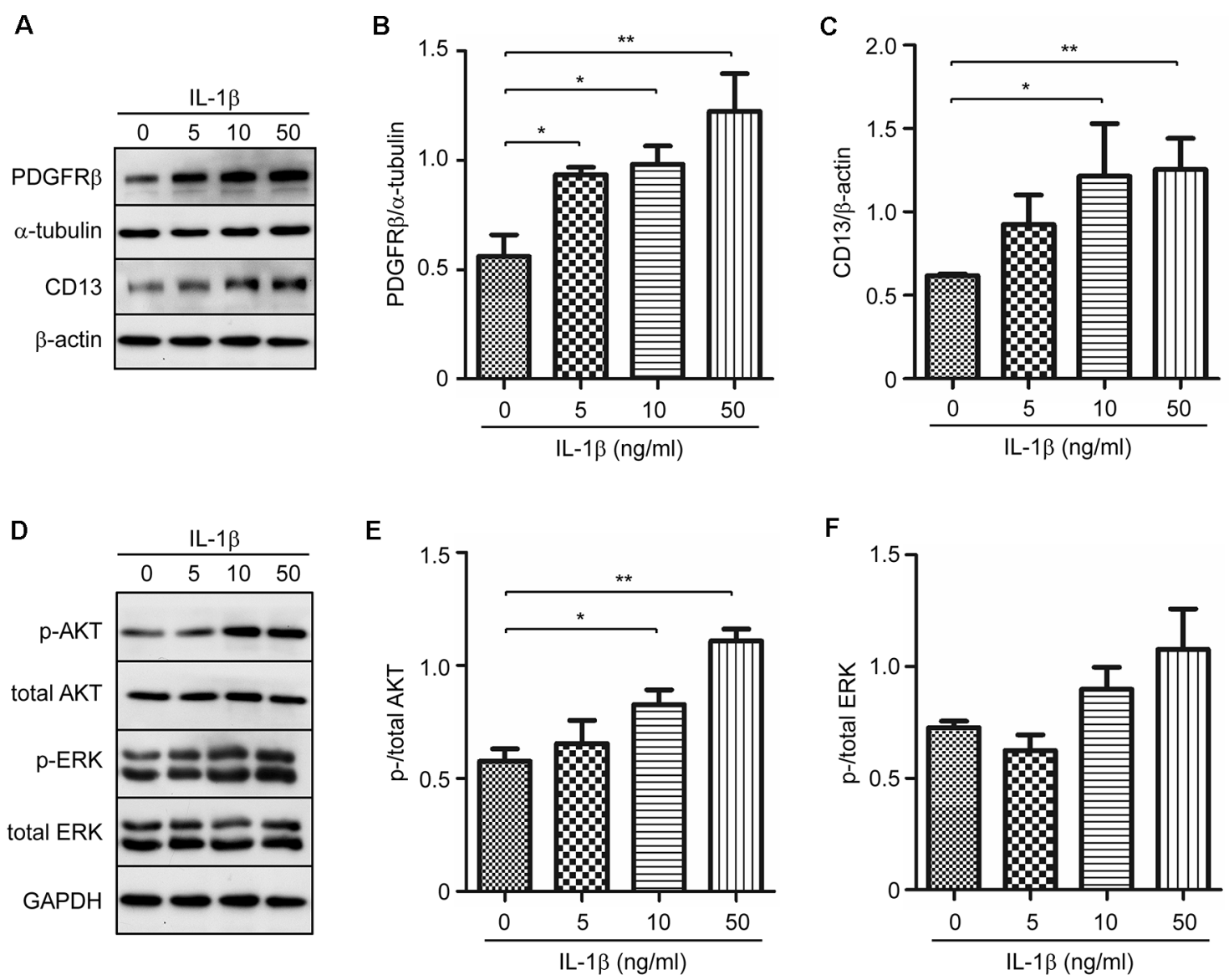

FIGURE 5 | IL-1 $\beta$ increases protein expression of PDGFR $\beta$ and CD13 in cultured pericytes. Pericytes were cultured and treated with recombinant human IL-1 $\beta$ at 0 , 5, 10, and $50 \mathrm{ng} / \mathrm{ml}$ for $24 \mathrm{~h}$. (A,D) Western blot was used to detect PDGFR $\beta$ and CD13, as well as phosphorylated and total protein levels of AKT and ERK. (B,C,E,F) Stimulation of IL-1 $\beta$ increases protein levels of PDGFR $\beta$ and CD13, and activates phosphorylation of AKT, but not ERK, in a dose-dependent manner. One-way ANOVA followed by Tukey post hoc test, $n=3$ per group. ${ }^{\star} p<0.05$ and ${ }^{\star *} p<0.01$.

In additional experiments, we treated cultured pericytes with recombinant IL-1 $\beta$ cytokine. IL- $1 \beta$ at 5,10 and $50 \mathrm{ng} / \mathrm{ml}$ did not alter the cell proliferation as measured with MTT assay (Figure 3I; $n=3$ per group).

\section{NLRP3 Inhibition Attenuates the Expression of PDGFR $\beta$ and CD13 in Cultured Pericytes}

PDGFR $\beta$ and CD13 are two protein markers of pericytes in the brain, which mediate the physiological and pathophysiological functions of pericytes (Lindahl et al., 1997; Rangel et al., 2007). We observed that treatments with MCC950 inhibited expression of PDGFR $\beta$ and CD13 in pericytes in a dose-dependent manner (Figures 4A-C; one-way ANOVA, $p<0.05$; $n=4$ per group). To analyze underlying mechanisms, through which NLRP3 drives pericyte differentiation, we detected phosphorylation of AKT, ERK, and NF- $\mathrm{B}$ in MCC950-treated cells. Activation of AKT and ERK is involved in pericyte proliferation and migration (Bonacchi et al., 2001; Yao et al., 2014). We observed that inhibition of NLRP3 reduced the protein levels of both phosphorylated AKT and ERK in a dose-dependent manner (Figures 4D-F; one-way ANOVA, $p<0.05 ; n=4$ per group). However, phosphorylation of NF- $\kappa \mathrm{B}$ in pericytes was not significantly altered by treatments with MCC950 (Figures 4G,H; one-way ANOVA, $p=0.094$; $n=3$ per group).

\section{IL-1 $\beta$ Increases the Expression of PDGFR $\beta$ and CD13 in Cultured Pericytes}

Although IL-1 $\beta$ did not increase pericyte proliferation (Figure 3I), we hypothesized that IL-1 $\beta$ might affect the differentiation of pericytes. We treated cultured pericytes with IL- $1 \beta$ at different concentrations. IL-1 $\beta$ did increase the protein expression of PDGFR $\beta$ and CD13 also with a concentration-dependent pattern (Figures 5A-C; one-way ANOVA, $p<0.05 ; n=3$ per group). As potential mechanisms mediating effects of IL- $1 \beta$ activation, we observed that IL- $1 \beta$ treatments significantly increased phosphorylation of AKT but not of ERK (Figures 5D-F; one-way ANOVA, $p<0.05$; $n=3$ per group). 


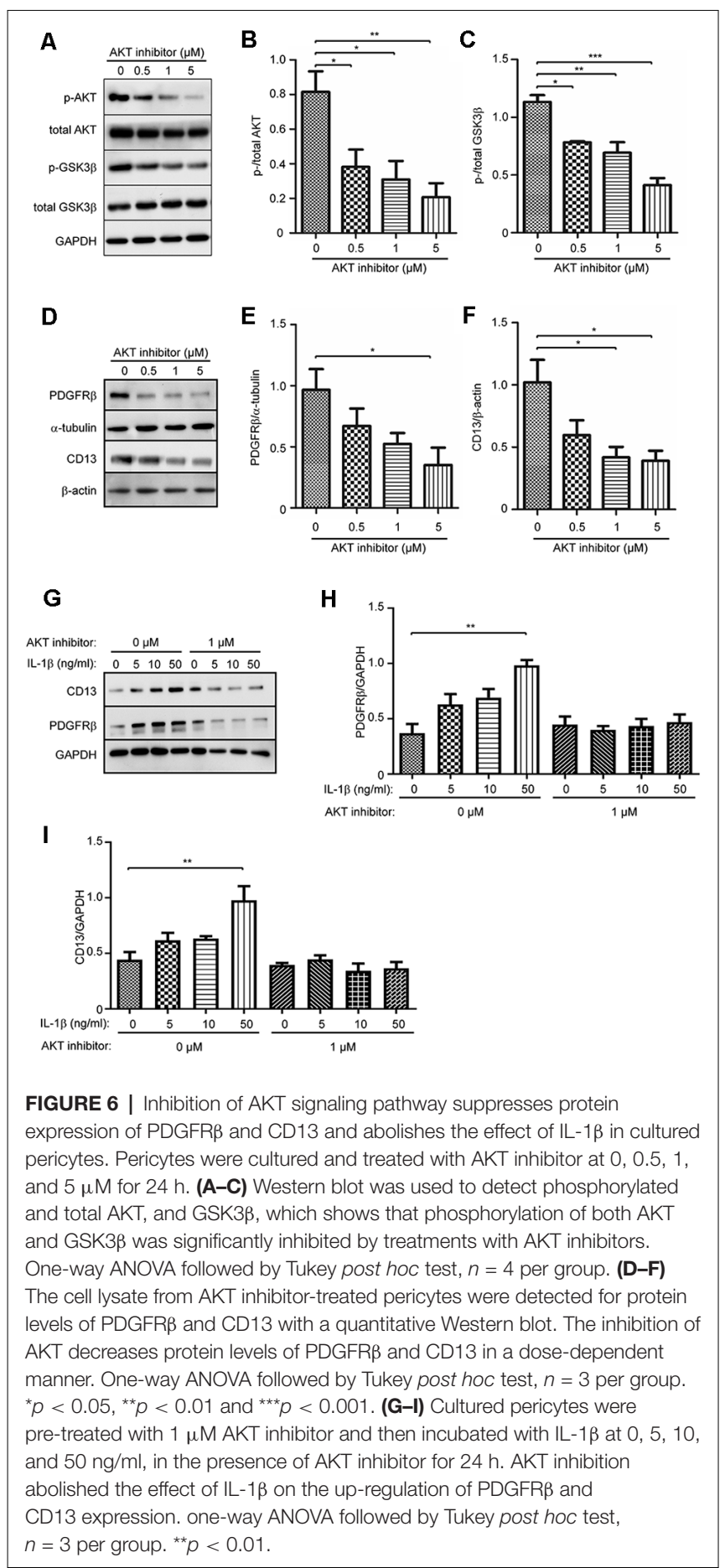

\section{Inhibition of AKT Suppresses Expression of PDGFR $\beta$ and CD13 in Cultured Pericytes}

As activation of AKT in pericytes was suppressed by NLRP3 inhibition but enhanced upon IL-1 $\beta$ activation, we supposed that AKT signaling plays a key role in the differentiation of pericytes. We treated pericytes with AKT inhibitors at $0,0.5,1$, and $5 \mu \mathrm{M}$. Phosphorylation of AKT and phosphorylation of GSK3 $\beta$, a kinase down-stream to AKT, were both reduced (Figures $6 \mathrm{~A}-\mathrm{C}$; one-way ANOVA, $p<0.05 ; n=4$ per group), which verified the successful inhibition of AKT signaling. With such an inhibition, expression of both PDGFR $\beta$ and CD13 was significantly down-regulated in a dose-dependent manner (Figures 6D-F; one-way ANOVA, $p<0.05$; $n=3$ per group).

In the following experiments, we treated cultured pericytes with IL-1 $\beta$ at different concentrations in the presence and absence of $1 \mu \mathrm{M}$ AKT inhibitor. Without co-treatment of AKT inhibitor, IL-1 $\beta$ activation did increase the expression of PDGFR $\beta$ and CD13 in pericytes (Figures 6G-I; one-way ANOVA, $p<0.05 ; n=3$ per group), which corroborated our previous experiments (see Figure 5). Interestingly, inhibition of AKT abolished the effect of IL$1 \beta$ on the up-regulation of PDGFR $\beta$ and CD13 proteins in pericytes (Figures 6G-I; one-way ANOVA, $p>0.05$; $n=3$ per group).

\section{DISCUSSION}

Pericytes play a central role in regulating microvascular circulation and BBB function in the brain (Sweeney et al., 2016). Our study demonstrated that the deletion of NLRP3 under physiological conditions decreases the coverage of pericytes and protein levels of PDGFR $\beta$ and CD13 in cerebral blood vessels. PDGFR $\beta$ and CD13, together with neural/glial antigen-2 and CD146 are expressed in capillary-associated pericytes, and often used as protein markers of brain pericytes (Smyth et al., 2018). PDGFR $\beta$ and CD13 also trigger proliferation and migration of pericytes after stimulation with angiogenesis-associated growth factors (Lindahl et al., 1997; Rangel et al., 2007). Thus, the reduction of CD13 and PDGFR $\beta$ represents not only the loss of pericytes but also the dysfunction of pericytes in the brain. Indeed, we observed that the deletion of NLRP3 reduces the vasculature in the brain, which corroborates a recent observation that the dysfunction of pericytes decreases the length of cerebral blood vessels in PDGFR $\beta$-mutated mouse brain (Montagne et al., 2018). Our study suggests that NLRP3 is essential in the maintenance of functional pericytes in healthy brains. We did not observe the leakage of IgG from serum into brain parenchyma in NLRP3-deficient mice. However, we could not exclude the impairment in the ultrastructure of $\mathrm{BBB}$, which might be caused by the lack of NLRP3.

NLRP3-contained inflammasome activates caspase-1 and produces active IL-1 $\beta$ (Gross et al., 2011). MyD88 mediates inflammatory activation after the challenges of TLRs ligands and IL-1 $\beta$ (O’Neill and Bowie, 2007). We observed that deficiency of either NLRP3 or MyD88 decreases protein levels of PDGFR $\beta$ and CD13 in the mouse brain. We supposed that NLRP3 drives a basal inflammatory activation in pericytes and promotes pericyte survival, although it was difficult to detect the secretion of IL-1 $\beta$ from pericytes in the brain. In cultured pericytes, we did observe that caspase-1 is activated and inhibition of NLRP3 attenuates 
phosphorylation of multiple inflammation-related kinases, such as AKT and ERK, and perhaps also NFKB ( $p=0.094)$, which is correlated with decreased cell proliferation and PDGFR $\beta$ and CD13 expression. Moreover, treatments with IL- $1 \beta$ increase PDGFR $\beta$ and CD13 expression in our cultured pericytes. It is consistent with a report that TNF- $\alpha$ at $10 \mathrm{ng} / \mathrm{ml}$ promotes cultured pericytes to proliferate and migrate (Tigges et al., 2013). Thus, it is not surprising that angiogenesis is activated with pericyte proliferation in inflammatory lesion sites of multiple sclerosis (Girolamo et al., 2014). However, we observed that IL-1 $\beta$ treatments did not increase pericyte proliferation, which suggests that the regulation of pericyte proliferation by NLRP3 might not depend on IL-1 $\beta$ production. During early wound healing, NLRP3 facilitates angiogenesis; and the production of IL$1 \beta$ was not always necessary for this repair process, either (Weinheimer-Haus et al., 2015).

As there are no pericyte-specific NLRP3-knockout mice available, we had to work on animals with an overall deficiency of NLRP3. We know that NLRP3 is expressed also in non-pericyte brain cells, i.e., microglia (Heneka et al., 2013). We cannot exclude the possibility that NLRP3 deficiency in microglia decreases the coverage of pericytes in brain vessels. Microglia, located at the perivascular space, is the major component of the neurovascular unit. In response to systemic inflammation, microglia protect BBB integrity in an initial phase by expressing tight-junction protein Claudin-5 and turn to damage BBB through phagocytizing astrocytic end-feet after the inflammation is sustained (Haruwaka et al., 2019). However, the regulation of BBB function and especially pericyte activation by blood vesselassociated microglia under physiological conditions has not been fully explored.

It should be noted that NLRP3 might not fully offer protective effects on pericytes when the inflammatory activation surrounding pericytes is uncontrolled. In the AD brain, NLRP3-contained inflammasome is activated (Heneka et al., 2013), whereas, pericytes are impaired and lost (Sengillo et al., 2013; Nation et al., 2019). There must be other mechanisms, which damage pericytes, compensating for the protective effects of NLRP3 activation. For example, brain-delivered neurotrophic factor (BDNF) drops down and the activation of the BDNF receptor, TrkB, is impaired in the AD brain (Tanila, 2017). TrkB signaling regulates pericyte migration. The deletion of TrkB in pericytes reduces pericyte density and causes abnormal vasculogenesis in the heart (Anastasia et al., 2014). The deletion of NLRP3 in APP or Tau-transgenic mice was reported to rescue neuronal functions and shift microglial activation from pro-inflammatory to anti-inflammatory profile (Heneka et al., 2013; Ising et al., 2019). Unfortunately, the microvascular circulation in NLRP3-deficient AD mice has not been investigated.

AKT is a known kinase to regulate cell survival, proliferation, and angiogenesis in response to extracellular signals (Manning and Cantley, 2007). AKT activation prevents pericyte loss in diabetic retinopathy (Yun et al., 2018). In our experiments, AKT phosphorylation is reduced by NLRP3 inhibition but enhanced by IL-1 $\beta$ activation. Inhibition of AKT directly down-regulates the expression of PDGFR $\beta$ and CD13 and also abolishes the effect of IL-1 $\beta$ to elevate the protein levels of PDGFR $\beta$ and CD13 in pericytes. Thus, AKT activation might mediate the protective effects of NLRP3 in pericytes. As PDGFR $\beta$ activation induces phosphorylation of AKT (Lehti et al., 2005), PDGFR $\beta$ and AKT even activate each other and form positive feedback to maintain the healthy pericytes in the brain.

In summary, our study suggested that NLRP3 activation maintains healthy pericytes in the brain through activating AKT signaling pathway. In the following studies, we are evaluating potential cerebral vascular impairment in AD mice with both genetic and pharmacological inhibitions of NLRP3. The potential adverse effects of NLRP3 inhibition on pericyte function and microcirculation should be considered when NLRP3 inhibitors are administered to treat $\mathrm{AD}$ or other inflammatory disorders.

\section{DATA AVAILABILITY STATEMENT}

The original contributions presented in the study are included in the article, further inquiries can be directed to the corresponding author.

\section{ETHICS STATEMENT}

The animal study was reviewed and approved by Landesamt für Verbraucherschutz, Saarland.

\section{AUTHOR CONTRIBUTIONS}

YL designed the study and wrote the manuscript. WQ, QL and QT conducted experiments, acquired data and analyzed data. TF provided pericyte cell line. DL and KF supervised the study. All authors contributed to the article and approved the submitted version.

\section{FUNDING}

This work was funded by National Natural Science Foundation of China (Grant 81771371 to YL and Grant 81902984 to WQ), SNOWBALL, an EU Joint Programme for Neurodegenerative Disease (JPND; 01ED1617B; to YL and KF) and China Scholarship Council (CSC; 201906820011; to QL). We acknowledge support by the Deutsche Forschungsgemeinschaft (DFG, German Research Foundation) and Saarland University within the funding programme Open Access Publishing. The older version of this manuscript has been released as a pre-print at Research Square (Quan et al., 2019).

\section{ACKNOWLEDGMENTS}

We thank Inge Tomic and Isabel Euler for their perfect technical support. 


\section{REFERENCES}

Adachi, O., Kawai, T., Takeda, K., Matsumoto, M., Tsutsui, H., Sakagami, M., et al. (1998). Targeted disruption of the MyD88 gene results in loss of IL1- and IL-18-mediated function. Immunity 9, 143-150. doi: 10.1016/s10747613(00)80596-8

Anastasia, A., Deinhardt, K., Wang, S., Martin, L., Nichol, D., Irmady, K., et al. (2014). Trkb signaling in pericytes is required for cardiac microvessel stabilization. PLoS One 9:e87406. doi: 10.1371/journal.pone. 0087406

Bonacchi, A., Romagnani, P., Romanelli, R. G., Efsen, E., Annunziato, F., Lasagni, L., et al. (2001). Signal transduction by the chemokine receptor CXCR3: activation of Ras/ERK, Src and phosphatidylinositol 3-kinase/Akt controls cell migration and proliferation in human vascular pericytes. J. Biol. Chem. 276, 9945-9954. doi: 10.1074/jbc.m010 303200

Boulay, A. C., Saubamea, B., Decleves, X., and Cohen-Salmon, M. (2015). Purification of mouse brain vessels. J. Vis. Exp. 105:e53208. doi: 10.3791/53208

Decker, Y., Muller, A., Nemeth, E., Schulz-Schaeffer, W. J., Fatar, M., Menger, M. D., et al. (2018). Analysis of the vasculature by immunohistochemistry in paraffin-embedded brains. Brain Struct. Funct. 223, 1001-1015. doi: 10.1007/s00429-017-1595-8

Dempsey, C., Rubio Araiz, A., Bryson, K. J., Finucane, O., Larkin, C., Mills, E. L., et al. (2017). Inhibiting the NLRP3 inflammasome with MCC950 promotes non-phlogistic clearance of amyloid-beta and cognitive function in APP/PS1 mice. Brain Behav. Immun. 61, 306-316. doi: 10.1016/j. bbi.2016.12.014

Deture, M. A., and Dickson, D. W. (2019). The neuropathological diagnosis of Alzheimer's disease. Mol. Neurodegener. 14:32. doi: 10.1186/s13024-0190333-5

Girolamo, F., Coppola, C., Ribatti, D., and Trojano, M. (2014). Angiogenesis in multiple sclerosis and experimental autoimmune encephalomyelitis. Acta Neuropathol. Commun. 2:84. doi: 10.1186/s40478-014-0084-z

Gross, O., Thomas, C. J., Guarda, G., and Tschopp, J. (2011). The inflammasome: an integrated view. Immunol. Rev. 243, 136-151. doi: 10.1111/j.1600-065x.2011. 01046.x

Guijarro-Muñoz, I., Compte, M., Alvarez-Cienfuegos, A., Alvarez-Vallina, L., and Sanz, L. (2014). Lipopolysaccharide activates Toll-like receptor 4 (TLR4)-mediated NF-кB signaling pathway and proinflammatory response in human pericytes. J. Biol. Chem. 289, 2457-2468. doi: 10.1074/jbc.m113. 521161

Hao, W., Liu, Y., Liu, S., Walter, S., Grimm, M. O., Kiliaan, A. J., et al. (2011). Myeloid differentiation factor 88-deficient bone marrow cells improve Alzheimer's disease-related symptoms and pathology. Brain 134, 278-292. doi: 10.1093/brain/awq325

Haruwaka, K., Ikegami, A., Tachibana, Y., Ohno, N., Konishi, H., Hashimoto, A., et al. (2019). Dual microglia effects on blood brain barrier permeability induced by systemic inflammation. Nat. Commun. 10:5816. doi: 10.1038/s41467-01913812-z

Heneka, M. T., Kummer, M. P., Stutz, A., Delekate, A., Schwartz, S., VieiraSaecker, A., et al. (2013). NLRP3 is activated in Alzheimer's disease and contributes to pathology in APP/PS1 mice. Nature 493, 674-678. doi: $10.1038 /$ nature 11729

Ising, C., Venegas, C., Zhang, S., Scheiblich, H., Schmidt, S. V., Vieira-Saecker, A., et al. (2019). NLRP3 inflammasome activation drives tau pathology. Nature 575, 669-673. doi: 10.1038/s41586-019-1769-Z

Kovac, A., Erickson, M. A., and Banks, W. A. (2011). Brain microvascular pericytes are immunoactive in culture: cytokine, chemokine, nitric oxide and LRP-1 expression in response to lipopolysaccharide. J. Neuroinflammation 8:139. doi: 10.1186/1742-2094-8-139

Leaf, I. A., Nakagawa, S., Johnson, B. G., Cha, J. J., Mittelsteadt, K., Guckian, K. M., et al. (2017). Pericyte MyD88 and IRAK4 control inflammatory and fibrotic responses to tissue injury. J. Clin. Invest. 127, 321-334. doi: 10.1172/ jci87532

Lehti, K., Allen, E., Birkedal-Hansen, H., Holmbeck, K., Miyake, Y., Chun, T. H., et al. (2005). An MT1-MMP-PDGF receptor-beta axis regulates mural cell investment of the microvasculature. Genes Dev. 19, 979-991. doi: 10.1101/gad. 1294605
Lindahl, P., Johansson, B. R., Leveen, P., and Betsholtz, C. (1997). Pericyte loss and microaneurysm formation in PDGF-B-deficient mice. Science 277, 242-245. doi: $10.1126 /$ science.277.5323.242

Love, S., and Miners, J. S. (2016). Cerebrovascular disease in ageing and Alzheimer's disease. Acta Neuropathol. 131, 645-658. doi: 10.1007/s00401-015$1522-0$

Manning, B. D., and Cantley, L. C. (2007). AKT/PKB signaling: navigating downstream. Cell 129, 1261-1274. doi: 10.1016/j.cell.2007.06.009

Martinon, F., Petrilli, V., Mayor, A., Tardivel, A., and Tschopp, J. (2006). Goutassociated uric acid crystals activate the NALP3 inflammasome. Nature 440, 237-241. doi: 10.1038/nature04516

Montagne, A., Nikolakopoulou, A. M., Zhao, Z., Sagare, A. P., Si, G., Lazic, D., et al. (2018). Pericyte degeneration causes white matter dysfunction in the mouse central nervous system. Nat. Med. 24, 326-337. doi: 10.1038/nm.4482

Nation, D. A., Sweeney, M. D., Montagne, A., Sagare, A. P., D’Orazio, L. M., Pachicano, M., et al. (2019). Blood-brain barrier breakdown is an early biomarker of human cognitive dysfunction. Nat. Med. 25, 270-276. doi: 10.1038/s41591-018-0297-y

Nyúl-Tóth, A., Kozma, M., Nagyőszi, P., Nagy, K., Fazakas, C., Haskó, J., et al. (2017). Expression of pattern recognition receptors and activation of the non-canonical inflammasome pathway in brain pericytes. Brain Behav. Immun. 64, 220-231. doi: 10.1016/j.bbi.2017.04.010

O’Neill, L. A., and Bowie, A. G. (2007). The family of five: TIR-domain-containing adaptors in Toll-like receptor signalling. Nat. Rev. Immunol. 7, 353-364. doi: 10.1038/nri2079

Quan, W. Q., Luo, Q. H., Tang, Q. Q., Furihata, T., Li, D., Fassbender, K., et al. (2019). NLRP3 maintains healthy pericytes in the brain. [Preprint]. (Version 1). doi: $10.21203 / \mathrm{rs} .2 .18793 / \mathrm{v} 1$

Rangel, R., Sun, Y., Guzman-Rojas, L., Ozawa, M. G., Sun, J., Giordano, R. J., et al. (2007). Impaired angiogenesis in aminopeptidase N-null mice. Proc. Natl. Acad. Sci. U S A 104, 4588-4593. doi: 10.1073/pnas.0611653104

Sagare, A. P., Bell, R. D., Zhao, Z., Ma, Q., Winkler, E. A., Ramanathan, A., et al. (2013). Pericyte loss influences Alzheimer-like neurodegeneration in mice. Nat. Commun. 4:2932. doi: 10.1038/ncomms3932

Sengillo, J. D., Winkler, E. A., Walker, C. T., Sullivan, J. S., Johnson, M., and Zlokovic, B. V. (2013). Deficiency in mural vascular cells coincides with bloodbrain barrier disruption in Alzheimer's disease. Brain Pathol. 23, 303-310. doi: 10.1111/bpa.12004

Smyth, L. C. D., Rustenhoven, J., Scotter, E. L., Schweder, P., Faull, R. L. M., Park, T. I. H., et al. (2018). Markers for human brain pericytes and smooth muscle cells. J. Chem. Neuroanat. 92, 48-60. doi: 10.1016/j.jchemneu.2018. 06.001

Stancu, I. C., Cremers, N., Vanrusselt, H., Couturier, J., Vanoosthuyse, A., Kessels, S., et al. (2019). Aggregated Tau activates NLRP3-ASC inflammasome exacerbating exogenously seeded and non-exogenously seeded Tau pathology in vivo. Acta Neuropathol. 137, 599-617. doi: 10.1007/s00401-01801957-y

Sweeney, M. D., Ayyadurai, S., and Zlokovic, B. V. (2016). Pericytes of the neurovascular unit: key functions and signaling pathways. Nat. Neurosci. 19 , 771-783. doi: 10.1038/nn.4288

Tanila, H. (2017). The role of BDNF in Alzheimer's disease. Neurobiol. Dis. 97, 114-118. doi: 10.1016/j.nbd.2016.05.008

Tigges, U., Boroujerdi, A., Welser-Alves, J. V., and Milner, R. (2013). TNF$\alpha$ promotes cerebral pericyte remodeling in vitro, via a switch from $\alpha 1$ to $\alpha 2$ integrins. J. Neuroinflammation 10:33. doi: 10.1186/1742-2094-10-33

Umehara, K., Sun, Y., Hiura, S., Hamada, K., Itoh, M., Kitamura, K., et al. (2018). A new conditionally immortalized human fetal brain pericyte cell line: establishment and functional characterization as a promising tool for human brain pericyte studies. Mol. Neurobiol. 55, 5993-6006. doi: 10.1007/s12035-0170815-9

Venegas, C., Kumar, S., Franklin, B. S., Dierkes, T., Brinkschulte, R., Tejera, D., et al. (2017). Microglia-derived ASC specks cross-seed amyloid- $\beta$ in Alzheimer's disease. Nature 552, 355-361. doi: 10.1038/ nature 25158

Weinheimer-Haus, E. M., Mirza, R. E., and Koh, T. J. (2015). Nod-like receptor protein-3 inflammasome plays an important role during early stages of wound healing. PLoS One 10:e0119106. doi: 10.1371/journal.pone.01 19106 
Yao, Q., Renault, M. A., Chapouly, C., Vandierdonck, S., Belloc, I., JaspardVinassa, B., et al. (2014). Sonic hedgehog mediates a novel pathway of PDGFBB-dependent vessel maturation. Blood 123, 2429-2437. doi: 10.1182/blood2013-06-508689

Yun, J. H., Jeong, H. S., Kim, K. J., Han, M. H., Lee, E. H., Lee, K., et al. (2018). $\beta$-Adrenergic receptor agonists attenuate pericyte loss in diabetic retinas through Akt activation. FASEB J. 32, 2324-2338. doi: 10.1096/fj. 201700570rr

Zudaire, E., Gambardella, L., Kurcz, C., and Vermeren, S. (2011). A computational tool for quantitative analysis of vascular networks. PLoS One 6:e27385. doi: 10.1371/journal.pone.0027385
Conflict of Interest: The authors declare that the research was conducted in the absence of any commercial or financial relationships that could be construed as a potential conflict of interest.

Copyright (c) 2020 Quan, Luo, Tang, Furihata, Li, Fassbender and Liu. This is an open-access article distributed under the terms of the Creative Commons Attribution License (CC BY). The use, distribution or reproduction in other forums is permitted, provided the original author(s) and the copyright owner(s) are credited and that the original publication in this journal is cited, in accordance with accepted academic practice. No use, distribution or reproduction is permitted which does not comply with these terms. 